\title{
Does A Long-Term and Active Customer of A Current Savings Account Have A High Lifetime Value?
}

\author{
Chun-Qing Li \\ Xi'an Technological University \\ E-Mail: team1990@163.com \\ Weverbergh Marcel \\ University of Antwerp \\ E-Mail: marcel.weverbergh@ua.ac.be \\ Ting Gao \\ Xi'an Technological University \\ E-Mail: gaoting1030@gmail.com
}

\begin{abstract}
A basic tenet of relationship marketing is that firms benefit more from maintaining long-term customers; however, it is not clear whether the need for maintaining personal banking services of long-term and active customers (e.g., current savings accounts) is in the best interest of bank profitability (Reinartz and Kumar, 2000). The primary objective of this study is to provide a rigorous and differentiated empirical analysis of the lifetime and active-profitability relationship in a non-contractual service context.

In this study, the authors find that, in personal bank service scenarios, the most valuable customers are those who are less active and have high account balances. Moreover, the correlation between customer activity, lifetime length, and profitability is not significantly positive; long customer lifetimes do not necessarily increase revenue or decrease the cost of customer service.

Furthermore, a large number of transactions do not necessarily indicate a high lifetime value, and not all active customers contribute to large bank profits. The authors develop plausible explanations for findings that go against available evidence in the literature, which can help managers focus their efforts on more profitable customers. The authors also draw several marketing implications and acknowledge the limitations of this study.
\end{abstract}

Keywords: CLV, RFM, NBD, Gamma-Gamma, Exponential Smoothing 


\section{INTRODUCTION}

A core belief that underlies customer relationship management is that marketing activities should focus on increasing customer lifetime value (CLV). To achieve an increase in CLV the company must create customer segments, and assign customer segment managers who can further develop customer-focused programs based on these beliefs. However, most corporations are not organized in this way, rather their compensation systems work to frustrate customer relationship building activities.

The move toward a customer-centric approach to marketing, coupled with the increasing availability of customer transaction data (enterprise level data warehouse), has led to an interest in both the notion and calculation of CLV (Fader, Hardie, and Lee, 2005). Further, this concept has rapidly gained acceptance as a metric in customer relationship management (CRM), which relates to acquiring, growing, and retaining the "right" customers (Gupta, Lehmann, and Stuart, 2004) and evaluate marketing decisions, strategies, and resource allocation efforts (Blattberg and Deighton, 1996; Rust, Lemon, and Zeithaml, 2004; Venkatesan and Kumar, 2004). However, it is still a relatively new concept in the service context, especially in retail banking.

Therefore, we attempt to combine the contributions of the literature about CLV with actual practice as applying to current savings account customers in retail banking and we offer a method to calculate the CLV. Specifically, three reasons encourage us to begin with the customers of current saving accounts:

First, in retail banking, there are almost $98-99 \%$ customers with current savings accounts, which are the basis for other products or services; therefore, this is a very important component of business in retail banking. The second reason is that there are two types of context when we calculate CLV, non-contractual and contractual (Reinartz and Kumar, 2000; Reinartz and Kumar, 2003). There are also two types of customers in banks: retail and commercial. For current retail savings accounts, the relationship between the customer and the bank is in a non-contractual scenario. In other words, the relationship is between a seller and buyer and is not governed by a contract or membership; after the initial set up, we can conduct research on the basis of conventional wisdom and prior literature in this context (Schmittlein, Morrison, and Colombo, 1987; Schmittlein and Peterson, 1994; Colombo and Jiang, 1999; Fader, Hardie, and Lee, 2005). The third reason is that banks currently have a good method to calculate customer or account profitability, and they also have good data from enterprise data warehouses. This richness of data provides researchers with a good chance to apply results in the bank service, capture the whole lifetime of the customer 
relationship, and the resulting CLV. All these activities that will increase the efficiency of the bank's daily grind.

To do this, a critical problem faced by banks is the measurement of the CLV. Researchers have suggested various methods using customer-level data to measure CLV (Reinartz and Kumar, 2000; Rust, Lemon, and Zeithaml, 2004; Schmittlein and Peterson, 1994; Berger and Nasr, 1998); however, this is not same in the context of service banks, especially for current savings accounts, where the most active customer may not be the most valuable customer. This is because the values of the customer depend on the balance kept in the bank, not on the money or number of transactions. Therefore we must consider the CLV of current savings accounts of banks in another way; specifically from the original definition of CLV and the real meaning of the value derived from a banking customer.

In measuring customer lifetime value, a common approach is to estimate the present value of the net benefist to the firm from the customer, generally measured as the revenues from the customer minus the costs to the firm for maintaining the relationship with the customer over time (Blattberg and Deighton, 1996).

One popular method that follows such an approach in a non-contractual context is the negative binomial distribution (NBD)/Pareto model, proposed by Schmittlein et al. (1987). The NBD/Pareto model is applied when customer lifetimes are not known with certainty (i.e., it is unknown when a customer stops doing business with a firm). Instead of fixed lifetimes the model assumes that individual customer lifetimes with the firm are exponentially distributed. As discussed by Schmittlein and Peterson (1994), in contexts where customer lifetimes are observed, the NBD/Pareto model has limitations and is not suitable.

\section{DEFINITION AND CALCULATION OF CLV}

\section{Definition of CLV of Current Savings Accounts}

We adapt the computational logic, as suggested by Berger\& Nasr (1998) and Jain \& Singh (2002), to arrive at the formula for the CLV of the current savings account customers in a commercial bank.

Customer lifetime value for a firm is the net profit to the firm from a customer over the entire life of transactions of that customer with the firm. Hence, the lifetime value of a customer for a firm is the net of the revenues that are obtained from that customer over the lifetime of transactions with that customer minus the cost of attracting, selling, and servicing that customer, taking into account the time value of money (Berger and Nasr, 1998). In retail banking, the customer's saving account CLV 
is the same as that in other industries; in other words, it is the net present value of the future cash flows generated by a customer's relationship with the bank.

The basic structural model of CLV is

$$
C L V=\sum_{t=1}^{n} \frac{\left(R_{t}-C_{t}\right)}{(1+d)^{t}}
$$

Where, $t$ is the period of cash flow from a customer transaction; $R_{t}$ is the revenue from the customer during period $t ; C_{t}$ is the total cost of generating the revenue $R_{t}$ during period $\mathrm{t}$; and $\mathrm{n}$ is the total number of periods of the projected life of the customer under consideration. This model defines a class of different CLV models based on the net present value (NPV) of future cash flows from customers. This basic idea of NPV is that it is captures the essence of such models. Some important features of these models are that they assume a fixed time intervals for the cash flows which are equal during each time period, they apply only to customers who do business with the firm, they ignore past and prospective customers, they ignore acquisition costs, they do not consider a number of important factors such as the stochastic nature of the purchase process and variations in the timing of cash flows are not accounted for. However they are very simple and easy to use. Berger and Nasr (1998) gave an excellent overview of some CLV models that were built on this basic model.

\section{Customer Profitability of Current Savings Account}

In the bank, there is an accepted method to calculate the $\mathrm{CP}$ (Customer Profitability) for the present period, where $\mathrm{CP}$ is the difference between revenues and costs in the basic structural model of CLV: $\mathrm{CP}=\mathrm{R}-\mathrm{C}$, for all activities of a bank. Specifically, in the bank context customer profitability can be defined as in (2):

$$
\mathrm{CP}=\mathrm{NIR}+\mathrm{OR}-\mathrm{DE}-\mathrm{IE}-\mathrm{RP}
$$

Where, NIR are the net interest revenues, OR are other revenues, DE are direct expenses, IE are indirect expenses and RP is a risk provision for the load (for saving business, $\mathrm{RP}=0$ ).

Net interest income (NIR) are the revenues that obtained from deposits and outstanding loans. NIR includes interest revenues, interest expenses, cost of funds (to loans), and value of funds (to deposits). Of note, one of the largest components of a bank's profitability is its NIR. Net interest revenue is, by far, the largest driver of product profitability and typically accounting for up to $80 \%$ of a bank's revenue (Coffey, 2001). 
Other income (OR) is generated by customer transaction services, such as, credit card annual fees, off-site cash fees, procedure fees and other intermediary service revenues.

Direct expenses (DE) are the costs of customer activities that can be attributed to the account (e.g., withdrawals, deposits, balance inquiries and transfer transactions). According to the definition of business rules, a bank's direct expenses include three categories: client transaction costs, VIP service charges and business costs.

Indirect costs (IE) are not directly associated with customer behavior, but include necessary costs that the bank must spend on serving clients and operating it's business. These include utilities, advertising fee, salaries, and so on.

Risk reserve (RP) is the compensation for credit risk that can be some provision for losses. Further, RP is applicable for loan accounts, including various types of loans, such as credit cards, discounts, and other types of advances.

For current savings account, we ignored OR and DE because they are of less importance for the $\mathrm{CP}$ and the necessary data were not recorded in the data warehouse during the data collection. Therefore, in this paper, we limit the analysis to the main contribution of the CP (Customer Profitability) which is NIR and IE:

$$
\mathrm{CP}=\mathrm{NIR}-\mathrm{IE}
$$

Where, NIR is VOF-COF; VOF is the value of fund, and COF is cost of fund.

$$
\mathrm{VOF}=\text { present average monthly balance } \times \text { annual FTP rate } / 12
$$

FTP includes a shortage of funds transfer price. For current savings accounts, it is complicated to define the FTP rate, because customers with current savings account can take their money from the bank at any moment; here we take the FTP rate as the minimum value that is equal to the short-term credit (within 6 months) interest rate of the national bank announced at that time.

$$
\mathrm{COF}=\text { present average monthly balance } \times \text { annual interest rate } / 12
$$

During the data collection, the annual interest and annual credit interest rate was changed many times; therefore we take the different annual rates, according to the People's Bank of China that were announced at different time; the annual interest rate and the annual FTP rate are shown in Table 1. 
Table 1 The Net Annual Interest Rate During the Trial time

\begin{tabular}{cccccccc}
\hline Time & 2008.08 & 2008.09 & 2008.10 & 2008.11 & 2008.12 & 2009.01 & $\begin{array}{c}\text { After } \\
2009.01\end{array}$ \\
\hline $\begin{array}{c}\text { Annual FTP } \\
\text { Rate }\end{array}$ & $6.57 \%$ & $6.21 \%$ & $6.12 \%$ & $6.03 \%$ & $5.04 \%$ & $4.86 \%$ & $4.86 \%$ \\
\hline $\begin{array}{c}\text { Annual } \\
\text { Interest Rate }\end{array}$ & $0.72 \%$ & $0.72 \%$ & $0.72 \%$ & $0.72 \%$ & $0.36 \%$ & $0.36 \%$ & $0.36 \%$ \\
\hline $\begin{array}{c}\text { Net Annual } \\
\text { Interest Rate }\end{array}$ & $5.85 \%$ & $5.49 \%$ & $5.4 \%$ & $5.31 \%$ & $4.68 \%$ & $4.5 \%$ & $4.5 \%$ \\
\hline
\end{tabular}

Note: The data originate from the People's Bank of China. Usually the implementation date of new interest rates is not exactly at the beginning or the end of the month; therefore, we determine interest rates according to the maximum days of implementation in the month.

Therefore, we can conclude:

$$
\mathrm{NIR}=\mathrm{VOF}-\mathrm{COF}=\mathrm{B}_{\mathrm{t}} \times \mathrm{NI}_{\mathrm{t}}=\mathrm{Bt} \times(\text { annual FTP rate }- \text { annual interest rate }) / 12 \text { (6) }
$$

Where, $\mathrm{B}_{\mathrm{t}}$ is the average monthly balance of the current savings account; $\mathrm{NI}_{\mathrm{t}}$ is the net interest rate at time $\mathrm{t}$.

IE is and indirect expense; however, for the current savings accounts, it is almost same as the service cost. According to activity-based costing systems, IE= balance change times $\times$ service cost allocation ratio. More generally, it considers the lifetime value as:

$$
C L V=\sum_{\mathrm{t}=1}^{n} \frac{C P_{t}}{(1+\mathrm{d})^{\mathrm{t}}}=\sum_{\mathrm{t}=1}^{n} \frac{B_{\mathrm{t}} \times \mathrm{N} I_{t}-I E}{(1+\mathrm{d})^{\mathrm{t}}}
$$

Where $\mathrm{t}$ is the period that a customer keeps the relationship with the bank; here, it is counted monthly; $\mathrm{d}$ is the monthly discount rate; $\mathrm{n}$ is the total number of periods of expected life for of the customer under consideration. In this model, it is assumed that all cash flows take place at the end of a time period.

\section{Monthly Discount}

The basic idea of a discount rate, from the company's perspective, is that the discount rate can be considered equal to the annual return on capital during the observation periods. Additionally, the annual return on capital can be obtained from the 
difference of the growth ratio of GDP (gross domestic product) and inflation, where assuming that GDP's growth is driven by capital. Usually, the inflation rate is equal to the CPI (consumer price index) growth rate. From the National Bureau of Statistics, we can obtain the GDP's and CPI's growth rate during the observation periods (from Aug. 2008 to Nov. 2009), then find the annul discount, and then divided this by 12 , to get the monthly discount.

The growth rate of GDP in 2008, was $9.0 \%$ and year to year the growth rate of CPI is $5.9 \%$. In 2009, the GDP's growth rate was $8.7 \%$, and the CPI growth rate was $-0.7 \%$ (a decrease) compared to the previous year.

Therefore, the annul discount rate was $3.1 \%(9.0 \%-5.9 \%)$ in $2008,9.4 \%$ $(8.7 \%+0.7 \%)$ in 2009 , and the monthly discount rate was $0.26 \%(3.1 \% / 12)$ in 2008 , and $0.78 \%(9.4 \% / 12)$ in 2009.

\section{Service Allocation Ratio}

Activity-Based Costing applied to in indirect costs for each cost database aims is to determine reasonable cost drivers. We can calculate the cost driver distribution rate using the following formula:

The cost driver distribution rate of cost database $=$ total cost driver of the cost database / total operating cost of the cost database

Cost object share of indirect costs $=$ cost drivers of the objects (operating volume) $x$ cost driver allocation ratio

Here, we take the service cost allocation ratio as 7.06, according to Li Xuxian (2005).

From this model we calculate the CLV model results, forecast, and apply to manage valuable customers. We characterized each customer's buying behaviors with two probability distributions: one for the probability of the account balance change and one for the balance on an individual transaction. The model we develop does not assume that any of the variables are normally distributed; we use the negative binomial (NBD) to predict the transaction times, combined with the Gamma-Gamma model to predict the average monthly account balance. Finally, we use these to predict the results to calculate the customer CLV.

\section{Balance Change Times}

First, we use the NBD model to predict transaction times; here, we assumed the every transaction could change the balance. Therefore, transactions also represent the 
balance change times. The transaction times are measured in months and we assume that they follow an NBD process;

$$
\operatorname{TIME} \sim \mathrm{NBD}(\alpha, \gamma)
$$

Where TIME measures the balance change time in months, and $\alpha, \gamma$ are the parameters of the NBD distribution. It is assumed the frequency of individual customer transactions, f, follows a Poisson distribution, with parameter $\lambda$, and due to customer heterogeneity, the average number of transactions per unit time, $\lambda$, are subject to a Gamma distribution.

The NBD is a generalization of the Poisson distribution and is useful in modeling overdispersed count data. Another flexible distribution to model over-dispersed data is the COM-Poisson distribution; however, in our application the NBD outperformed the COM-Poisson in its predictive ability. The probability mass function of the NBD distributions is as follows:

$$
P_{N B D}[F=f \mid \alpha, \gamma]=\frac{\Gamma(\gamma+f)}{\Gamma(\gamma) f !}\left(\frac{\alpha}{\alpha+1}\right)^{\gamma}\left(\frac{1}{\alpha+1}\right)^{f}
$$

In our study, we use 21,698 customer history transactions for modeling. We implement parameter estimates of the NBD model in Excel. The maximum likelihood estimates of the model parameters are as follows: $\alpha=0.1228, \gamma=0.3154$, and LL $=$ -506024.6 .

In order to forecast the future transactions in the history of transactions, Bayes theorem is applied:

$$
E\left[X=x_{2} \mid x_{1}\right]=\frac{\gamma+x_{1}}{\alpha+1}=\left(\frac{\alpha}{\alpha+1}\right) \frac{\gamma}{\alpha}+\left(\frac{1}{\alpha+1}\right) x_{1}
$$

Where $x_{2}$ is the expected number of transactions when the first time is, $x_{1}$, and $\gamma /$ $\alpha$, is the average number of transactions. Using this formula, we can use the number of transactions in the past to predict future customer transactions.

We further analyze the model accuracy; if, $\varepsilon$, denotes the average absolute percentage error in the last three-month period, we use the following formula:

$$
\varepsilon=\left|\frac{\sum y_{i}-\sum \hat{y}_{i}}{\sum y_{i}}\right| \times 100 \%
$$

Where, $\mathrm{y}_{\mathrm{i}}$, is the actual total number of balance change times from August 2009 to 
November 2009, and $\hat{y}_{i}$, is the expected number during this time. The results showed that $\varepsilon=0.2394$, proved sufficiently good forecast effects in general.

\section{Average Monthly Account Balance}

\section{- Gamma-Gamma Model}

We assume that the average monthly account balance follows a Gamma-Gamma process. Thus, we use a Gamma-Gamma model to predict average monthly account balance.

\section{BALANCE G-G $(\mathrm{u}, \mathrm{v}, \varphi)$}

Where, BALANCE, measures the average monthly account balance and $\mathrm{u}, \mathrm{v}, \varphi$, are the parameters of the Gamma-Gamma distribution. It is assumed that the customer account balance follows a Gamma distribution, because the account balance (debit or credit) can not be negative, therefore it is not suitable a for normal distribution. It is also assumed that the customer account balance, $u / \theta$, is subject to the Gamma distribution. To take into account the heterogeneity of customers, it is assumed that the mean of the Gamma distribution, $u / \theta$, changes for different customers. Therefore, we defined $u$ as a constant using $\theta$ to capture every different customer account balances. Thus, we derive the Gamma-Gamma Mixed function (Colombo and Jiang, 1999):

$$
g_{G-G}(m \mid u, v, \varphi)=\frac{\Gamma(u+v)}{\Gamma(u) \Gamma(v)}\left(\frac{m}{\varphi+m}\right)^{u}\left(\frac{\varphi}{\varphi+m}\right)^{v} \frac{1}{m}
$$

The sub-account balance refers to the average monthly account balance divded by the number of balance changes times during the observation period; here we used 2008.08-2009.07 data for a total of 12 months to forecast the sub-account balances of 2009.08-2009.11. Using the predicted sub-account balance, data is multiplied by the NBD predicted balance change times, and then we find the average monthly account balance.

We use 21,698 customers' history transaction data in the model to predict the average monthly account balance from August 2009 to November 2009. Next we implement parameter estimates of the Gamma-Gamma model by Excel. The maximum likelihood estimates of the model parameters are: $\mathrm{u}=0.2080, \mathrm{v}=1.273, \varphi=34851.49$, and $\mathrm{LL}=-182494$.

Using Bayes theory, we can forecast the account balance, conditional on the past number of transactions and the previous account balance: 


$$
E\left(\mathrm{~m}_{2} \mid \mathrm{m}_{1}, \mathrm{x}_{1}\right)=\frac{u\left(x_{1} m_{1}+\varphi\right)}{\left(u x_{1}+v-1\right)}=\left(\frac{v-1}{u x_{1}+v-1}\right) \frac{u \varphi}{v-1}+\left(\frac{u x_{1}}{u x_{1}+v-1}\right) m_{1}
$$

Where, $\mathrm{x} 1$, is the past number of balance change times; $\mathrm{m} 1$, is the average monthly account balance for the past; and $\mathrm{u}, \mathrm{v}$ and $\varphi$ is the estimated model parameters. Using this formula, we use the customer account balance over the past month to predict the future account balance.

Additionally, we test the model accuracy; the results yield $\varepsilon=0.2840$, which proved, sufficiently, good forecast effects, in general.

\section{- Exponential Smoothing}

Future average monthly account balances of savings accounts, can also be predicted by means of exponential smoothing. This forecasting method is the most widely used of all forecasting techniques as it requires little computation. This method is used when data patterns are horizontal. The equation to calculate an exponential smoothing is:

$$
F_{t}=a A_{t-1}+(1-a) F_{t-1}
$$

Where, $F_{t}$ is the forecast average monthly account balance for period $t ; A_{t-1}$ is the actual value of the time-series of the prior period; $F_{t-1}$ is the forecast made for the prior period; and $\mathrm{a}$ is the smoothing constant between zero and one.

The value of a determines the degree of smoothing and how responsive the model is to fluctuation in a time-series data. In this study, we define $\mathrm{F}_{0}=0$, and calculate a.

Where

$$
\alpha=\min \sum_{i=1}^{21698} \sqrt{\sum_{t=13}^{16}\left(\overline{B_{12}}-B_{t}\right)^{2}}
$$

Where $\overline{B_{12}}$ is average monthly account balance during 12 periods. The value for alpha is between 0 and 1 and is determined both by the nature of the data and the feeling by the forecaster as to what constitutes as a good response rate. A smoothing constant close to zero leads to a stable model while a constant close to one is highly reactive. Typically, constant values between 0.01 and 0.3 are used. (Attaran, 1992)

Next we implement a parameter estimate of exponential smoothing using Excel. The maximum likelihood estimates of the model parameters are: $\alpha=0.014187921$ and $\mathrm{LL}=817375694.9$. 


\section{Calculation}

The current savings account CLV model has been introduced before. We used the average monthly balance of current savings account multiplied by the net interest rate at that time to arrive at the NIR; balance change times multiplied by the service cost allocation ratio to arrive at IE; the difference between NIR and IE is the customer profitability. In addition, the CLV is the customer's profitability of all lifetime discounted values.

In the calculation of CLV, we assume that customers' transaction behavior in 2009.12 and after would be the same as in 2009.11; that is, the average monthly account balance and the balance change times remain unchanged. Then we calculate the customer's present value of its profits in the infinite period.

$$
a V=P_{1}+O P_{2}+\ldots+C P_{N}=\sum_{i=1}^{12} O_{i}+\sum_{i=13}^{16} O P_{i}+\sum_{i=17}^{N} O_{i}
$$

CLV calculations are divided into three phases, the first phase of the training period, $1-12 ; 13-16$ for the second stage of the forecast period, the third stage, $17-\mathrm{N}$ for the infinite life-cycle of the CLV. It is assumed that from period 17 and beyond are in a mature stage, and that their transaction behavior remains unchanged.

The third stage of the CLV can then be written sa:

$$
\begin{aligned}
& \sum_{\mathrm{i}=17}^{N} C_{\mathrm{i}}=\lim _{N \rightarrow \infty} P_{1}\left[\frac{1}{(1+d)^{17}}+\ldots+\frac{1}{(1+d)^{N}}\right] \\
& =\lim _{N \rightarrow \infty} P_{17} \frac{\frac{1}{(1+d)^{17}\left[1-\frac{1}{(1+d)^{N}}\right]}}{1-\frac{1}{1+d}}=\frac{C_{17}}{d(1+d)^{16}}
\end{aligned}
$$

The discount rate is $3.1 \%$ in 2008 and $9.4 \%$ in 2009 . In this paper, $d=0.26 \%$ in 2008 and $0.78 \% 2009$ and as mentioned, it is assumed that all cash flows take place at the end of the time period. The 21,698 customers history transaction data shows that their total CLV, from August 2008 to July 2009, is $¥ 20593794$ (in RMB); $¥ 7855982$ and a prediction of $¥ 8421446$ for the Gamma-Gamma model and 7400625 for the exponential smoothing model from August 2009 to November 2009 ; $¥ 257921021$ and prediction $¥ 266780551$ for the Gamma-Gamma model and 244180652 for the exponential smoothing model from November 2009 to an infinite time. The model accuracy test results show that $\varepsilon=0.0329119$ for the Gamma-Gamma model and 0.0495711 for the exponential smoothing model, providing sufficient forecast. 


\section{DATA}

Data is from an established China commercial bank and their customer current savings account transaction histories. The data of each customer include the aggregate value of all current accounts, including margin deposits, current savings, large deposits, payroll, personal finance deposits, structured deposits, education savings, installment savings, call deposit, domestic savings, credit card deposits and so on. All current savings accounts are a summary of these data. The ideal account balance data should capture every second transaction occasions. However, for this simple analysis process, it is still possible to gain some insight from the transaction; here, we use monthly average account balance to replace the circumstance. The monthly average account balance is the sum of daily balance of the month divided by the number in days of the month (30 days or 31 days), rather than the balance at the end of each month. Therefore, if we use average account balance as measuring unit, the number of transactions is the number of both debit and credit transactions and the transactions times linked with the average account balance changes. Of note, we assume that each transaction changes the balance.

We randomly selected 30,000 customers who opened their first current deposit account in August 2008. We collected data on their initial and subsequent (i.e., repeat) transactions through the end of November 2009. After data cleaning, we removed 8,302 customers; the remaining data, about 21,698 customers' history transaction data, was used for modeling. We first split the 16-month dataset into two periods. The first period is from August 2008 to July 2009, 12 months in all, which is used for model calibration; the second period is from August 2009 to November 2009, 4 months in all, which is used for customer behavior forecasting and model validation.

The data contains three dependent measures of primary interest regarding the balance change times (TIME) and average account balance (BALANCE). Figures 1 and 2 display histogram plots of the balance change times and of the average account balances, respectively, across all purchase occasions for the estimation sample.

On average, a customer's balance changes less than 10 times a month. The bulk of the transactions (more than 95\%) occur within 10 times of the previous purchase. In terms of average account balance, again there is considerable heterogeneity in the population. On average, a average account balance is about $¥ 1000$, with the bulk of transactions (more than $80 \%$ of all transactions) being less than $¥ 10000$. However, we observe about $4 \%$ of all purchases to be in excess of $¥ 100000$. 


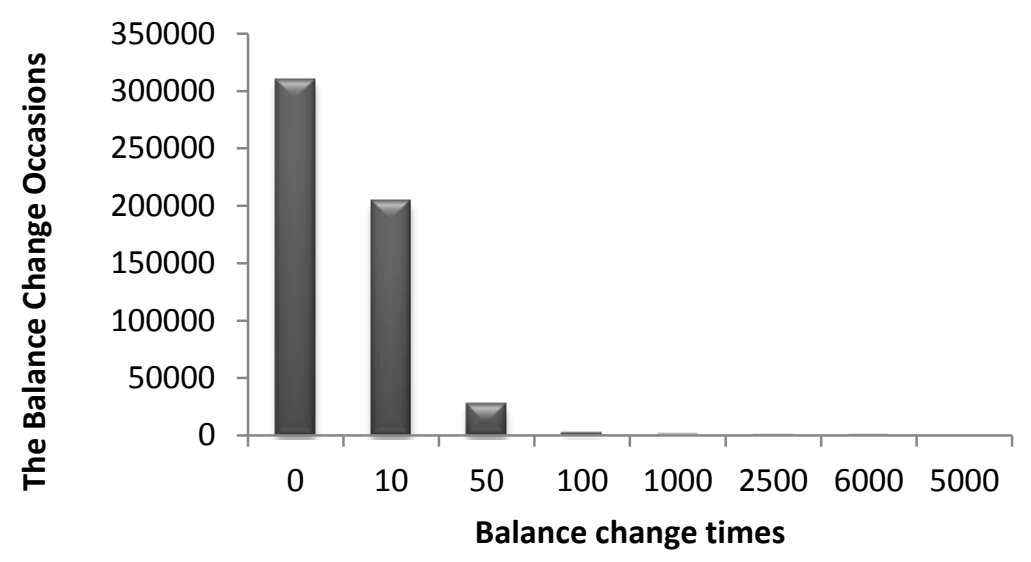

Figure 1 Balance change times

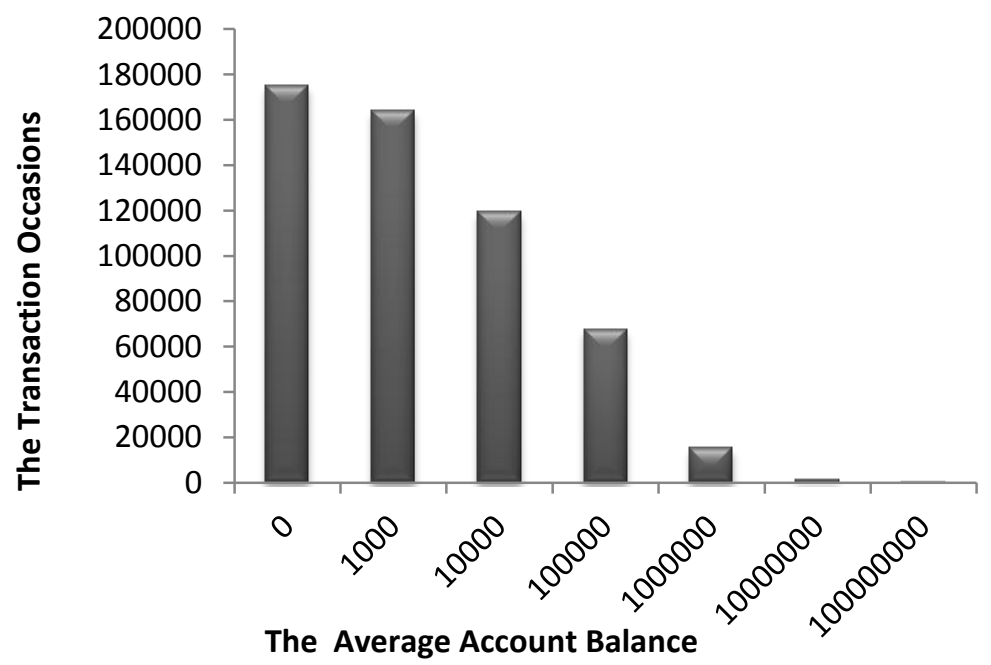

Figure 2 The Average Account Balance

\section{RESULTS}

\section{Balance Change Times}

In our study, we use 21,698 customers' history transaction data for modeling. We implement parameter estimates of the NBD model using Excel. The maximum likelihood estimates of the model parameters are: $\alpha=0.1228, \gamma=0.3154$, and $\mathrm{LL}=$ -506024.6 .

The model accuracy test results showed that $\varepsilon=0.2394$, which proved sufficiently, good forecast effects, in general. 


\section{Average Monthly Account Balance}

\section{- Gamma-Gamma Model}

We use 21,698 customers' history transaction data for modeling to predict the average monthly account balance from August 2009 to November 2009. We implement parameter estimates of the Gamma-Gamma model using Excel. The maximum likelihood estimates of the model parameters are: $\mathrm{u}=0.2402, \mathrm{v}=0.9052, \varphi$ $=10826.1969$, and $\mathrm{LL}=-182454.6524$.

Additionally, we test the model accuracy which show that $\varepsilon=0.2840$, proved, sufficiently, good forecast effects, in general.

\section{- Exponential Smoothing}

We implement parameter estimates of exponential smoothing method using Excel. The maximum likelihood estimates of the model parameters are: $\alpha=$ 0.014187921, and LL $=817375694.9$.

We also test the model accuracy, which yield $\varepsilon=2.9695$ and proved, sufficiently, good forecast effects in general.

\section{Calculation}

The discount rate was 3.1\% in 2008 and 9.4\% in 2009.In this paper, $d=0.26 \%$ in 2008 and $0.78 \%$ in 2009 and assumed that all cash flows took place at the end of a time period. The 21,698 customers’ history transaction data shows that their total CLV from August 2008 to July 2009 was $¥ 20593794$ (in RMB); $¥ 7855982$ and a prediction of $¥ 8421446$ for Gamma-Gamma model and 7400625 for exponential smoothing model from August 2009 to November 2009; $¥ 257921021$ and prediction $¥ 266780551$ for Gamma-Gamma model and $¥ 244180652$ for Exponential smoothing model in all from November 2009 to infinite time. The model accuracy test results show that $\varepsilon=$ 0.0329 for Gamma-Gamma model and 0.0496 for Exponential smoothing model, which proved, sufficiently, good forecast effects, in general.

Table 2 The Calculation of CLV

\begin{tabular}{ccccc}
\hline CLV & $2008.08-2009.07$ & $2009.08-2009.11$ & $2009.12-$ & Total \\
\hline Real & 20593794 & 7855982 & 257921021 & 286370797 \\
\hline $\begin{array}{c}\text { Gamma-Gamma \& } \\
\text { NBD }\end{array}$ & 20593794 & 8421446 & 266780551 & 295795792 \\
\hline ES \& NBD & 20593794 & 7400625 & 244180652 & 272175072 \\
\hline
\end{tabular}


Table 3 The Prediction Error

\begin{tabular}{cccc}
\hline Prediction Error & Total CLV & Model & \multirow{2}{*}{ NBD } \\
\hline Gamma-Gamma & 0.0329 & 0.2840 & \multirow{2}{*}{0.2394} \\
\hline Exponential Smoothing & 0.0496 & 2.9695 & \\
\hline
\end{tabular}

\section{CONCEPTUAL MODEL}

Individual customer lifetime profits are modeled as a function of a customer's lifetime duration, revenue flows over the course of a customer's lifetime, and firm costs associated with the marketing exchange. Conventional wisdom argues for a positive relationship between profitability and balance change times. Also the available evidence suggests that the lifetime-profitability relationship was positive, however, it might not be if the cost of serving the customer is greater than the profit margin generated by the customer. Another commonly held contention is that long-life customers are less costly to serve than are short-life customers. Thus, it may not be true that the costs of serving long-life customers are lower. In most banks, existing customers have more balance change times than do new ones, even after possible introductory offers are taken into account. This implies that the average account balance of customers and customer lifetime duration could be positively related. Some argue that customers who have been around long enough to learn a bank's procedures and acquaint themselves with its full service process will almost invariably realize greater value from the business relationship; therefore, it is not surprising that they are less sensitive on individual services.

To achieve this objective, we test the three propositions related to whether

1. There is a strong positive customer lifetime-profitability relationship,

2. Profits increase over time,

3. The costs of serving long-life customers are lower than those associated with short-life customers,

\section{Propositions 1}

$\mathrm{P}_{1}$ : There is a strong positive customer lifetime-profitability relationship.

We expect that the longer a customer's tenure with the firm and the higher the revenues of a customer, ceteris paribus, and the more profitable that customer will be. In line with the relationship marketing literature, we expected that customers who fall into Segment 1 could generate the highest profits. Likewise, we expect customers in Segment 4 to yield the lowest profits. However, in addition to providing empirical evidence for these expectations, this segmentation scheme enabled us to test the 
importance of the off-diagonal segments to the firm. An analysis of the off-diagonal quadrants could provide an answer to an important question: Could we encounter a situation in which customers with shorter tenure are more profitable are than long-term customers? This finding would run counter to the theoretical expectations of a relationship perspective. Furthermore, which group of customers is of more interest to the firm, the one that buys heavily for a short period (Segment 3) or the one with small spending but long-term commitment (Segment 2)? This is a particularly important question in combination with the size of the segments. That is, if the total number of customers in Segment 1 is comparably small, it is imperative for the firm to pay close attention to the characteristics of its second most profitable segment.

Table 4 The Nature of the Lifetime-Profitability Relationship Table

\begin{tabular}{|c|c|c|c|c|}
\hline \multirow{3}{*}{ Long Lifetime } & \multicolumn{2}{|c|}{ Segment 2} & \multicolumn{2}{|c|}{ Segment 1} \\
\hline & $\begin{array}{l}\text { Number of } \\
\text { Customers }\end{array}$ & $\begin{array}{l}\text { Lifetime Profit } \\
\text { per Customer }\end{array}$ & $\begin{array}{l}\text { Number of } \\
\text { Customers }\end{array}$ & $\begin{array}{l}\text { Lifetime Profit } \\
\text { per Customer }\end{array}$ \\
\hline & 5981 & -365.33 & 3881 & 2988.16 \\
\hline \multirow{3}{*}{ Short Lifetime } & \multicolumn{2}{|c|}{ Segment 4} & \multicolumn{2}{|c|}{ Segment 3} \\
\hline & 4868 & -158.68 & 6968 & 3439.19 \\
\hline & \multicolumn{2}{|c|}{ Low Lifetime Revenue } & \multicolumn{2}{|c|}{ High Lifetime Revenue } \\
\hline
\end{tabular}

\section{Propositions 2}

$\mathrm{P}_{2}$ : Profits increase over time.

To test the proposition of increasing profits over time, we (1) examine the profitability evolution visually and (2) analyze the sign of the slope coefficient. If profits were to increase over a customer's tenure, we would expect a positive slope parameter for the same variable. In addition to the linear effect, we include a dummy variable for the first purchase period to reflect the large first month purchase amount.

Table 5 The Nature of the Lifetime and Relative Profit Relationship Table

\begin{tabular}{lcccc}
\hline & \multicolumn{2}{c}{ Segment 2 } & \multicolumn{2}{c}{ Segment 1 } \\
\cline { 2 - 5 } Long Lifetime & $\begin{array}{c}\text { Number of } \\
\text { Customers }\end{array}$ & $\begin{array}{c}\text { Relative } \\
\text { Profit }\end{array}$ & $\begin{array}{c}\text { Number of } \\
\text { Customers }\end{array}$ & $\begin{array}{c}\text { Relative } \\
\text { Profit }\end{array}$ \\
\cline { 2 - 5 } & \multicolumn{5}{c}{5981} & -14.61 & 3881 & 119.53 \\
\cline { 2 - 5 } Short Lifetime & \multicolumn{2}{c}{ Segment 4 } & \multicolumn{2}{c}{ Segment 3 } \\
\cline { 2 - 5 } & \multicolumn{2}{c}{4868} & -6.35 & \multicolumn{2}{c}{ High Lifetime Revenue } \\
\cline { 2 - 5 }
\end{tabular}




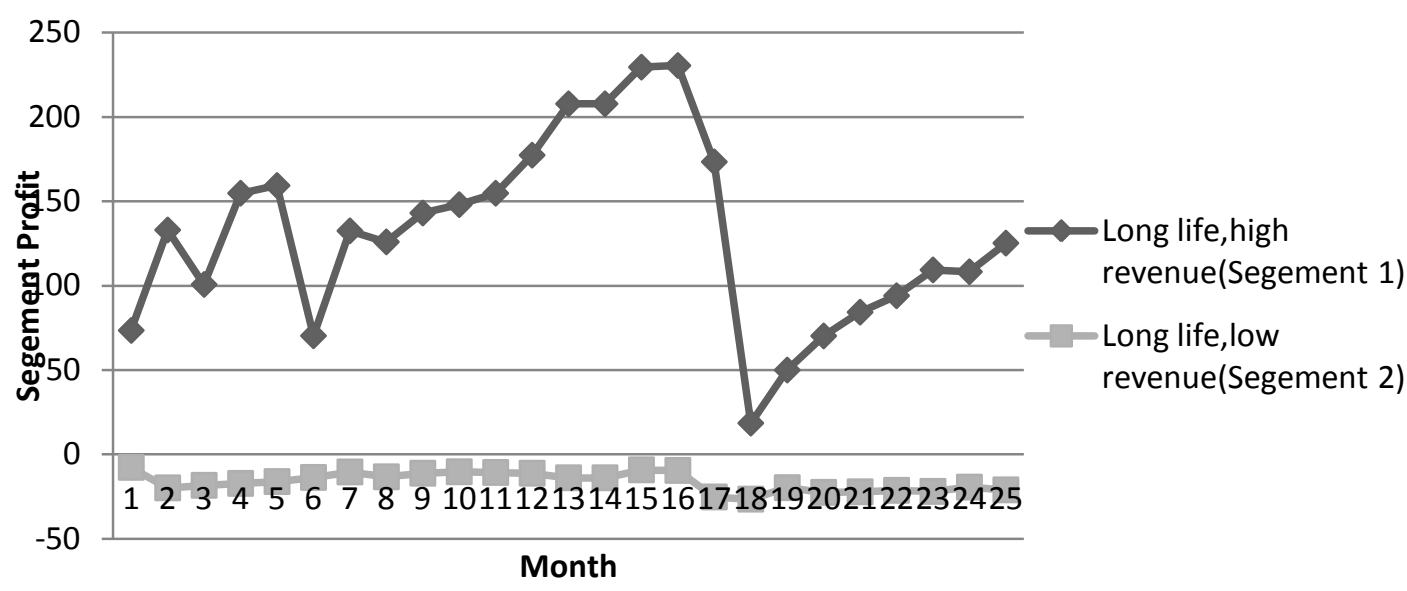

Figure 3 Aggregate Profits (RMB) for Long-Life Segments

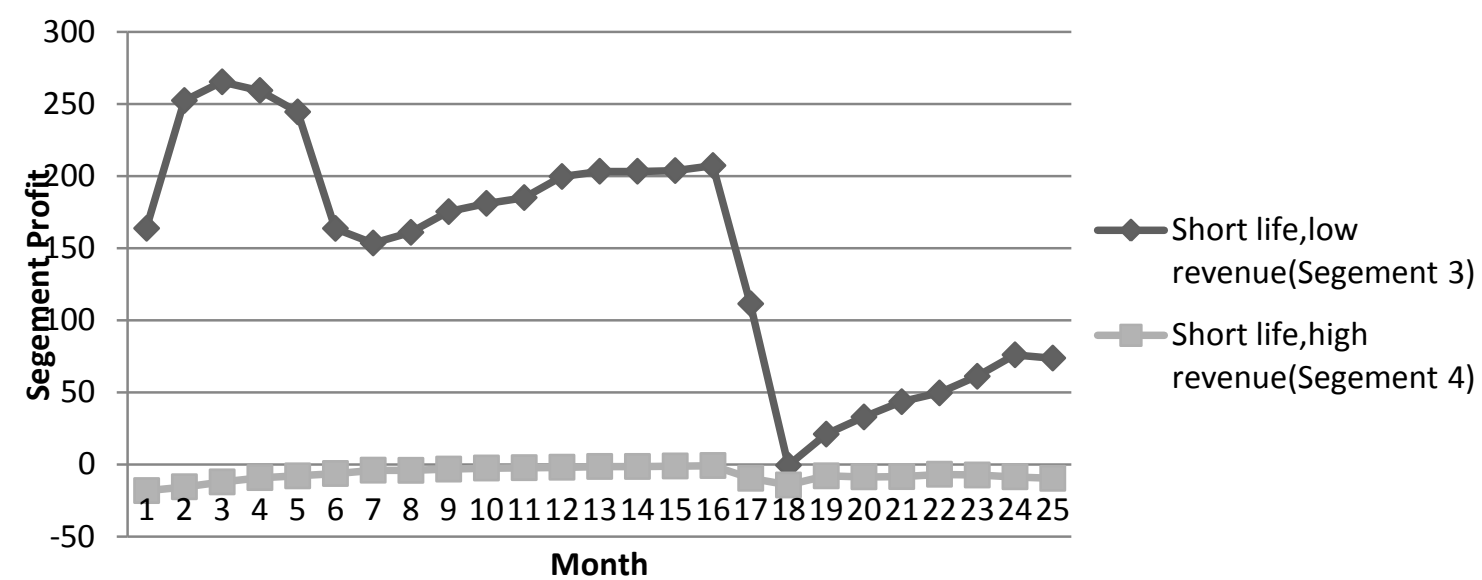

Figure 4 Aggregate Profits (RMB) for Short-Life Segments

Table 6 Regression Results

\begin{tabular}{ccccc}
\hline Segment & Intercept(a) & $\begin{array}{c}\text { Dummy Coefficient for } \\
\mathrm{t}=1\left(\mathrm{~b}_{1}\right)\end{array}$ & Coefficient for $\mathrm{t}\left(\mathrm{b}_{2}\right)$ & $\mathrm{R}^{2}$ \\
\hline 1 & 232.607 & 927.307 & 2.007 & 0.007 \\
\hline 2 & 14.912 & -68.463 & -1.098 & 0.060 \\
\hline 3 & 802.180 & 10.681 & -22.557 & 0.003 \\
\hline 4 & 14.758 & -20.399 & -0.572 & 0.029 \\
\hline
\end{tabular}




\section{Propositions 3}

$\mathrm{P}_{3}$ : The costs of serving long-life customers are lower than those associated with short-life customers.

To test this proposition, we compute the ratio of promotional costs in a given period over the revenues in that same period. Promotional costs are the total cost of producing and mailing promotions and catalogs, starting with the birth of the customer. This will vary for each customer depending on their purchase transaction history. Within each segment, we compute the mean promotional costs across all households and then compare these costs across segments to determine whether the costs of serving long-life customers are lower.

Table 7 The Nature of the Lifetime and Cost Relationship Table

\begin{tabular}{|c|c|c|c|c|}
\hline \multirow{3}{*}{ Long Lifetime } & \multicolumn{2}{|c|}{ Segment 2} & \multicolumn{2}{|c|}{ Segment 1} \\
\hline & $\begin{array}{l}\text { Number of } \\
\text { Customers }\end{array}$ & $\begin{array}{l}\text { Lifetime Cost } \\
\text { per Customer }\end{array}$ & $\begin{array}{l}\text { Number of } \\
\text { Customers }\end{array}$ & $\begin{array}{l}\text { Lifetime Cost } \\
\text { per Customer }\end{array}$ \\
\hline & 3043 & 633.97 & 133 & 1080.20 \\
\hline \multirow{3}{*}{ Short Lifetime } & \multicolumn{2}{|c|}{ Segment 4} & \multicolumn{2}{|c|}{ Segment 3} \\
\hline & 15811 & 322.78 & 2711 & 960.12 \\
\hline & \multicolumn{2}{|c|}{ Low Lifetime Revenue } & \multicolumn{2}{|c|}{ High Lifetime Revenue } \\
\hline
\end{tabular}

\section{SUMMARY AND CONCLUSION}

This paper present a new definition for CLV variables that are suitable for the background of the current savings business commercial bank, then present stochastic and exponential smoothing method to forecast customer behavior, and proposed the computational method of customer profit that reduces the cost using the customer income. Further we calculated CLV to be better manifested by the profit the customer brought to the bank and divided the valuable customer correctly. Finally, we validate the model by the financial event data of 21698 customers. The results show that the models fit the customer purchase frequency data and monetary value data accurately. And develop arguments that support and refute the three aforementioned propositions. In personal bank service scenarios, the most valuable customers are those who are less active and have high account balances. Moreover, the relationship between customer activity, lifetime length, and profitability is not a significantly positive correlation; long customer lifetimes do not necessarily increase revenue or decrease the cost of customer service. From these results, we can see that short lifetime customers also profitable and their profit is higher than long lifetime customers. The cost of high revenue customers 
is higher than low revenue customers. Additionally, with high revenue customers, the cost of long lifetime customers is a litter higher than it is for short lifetime customers; however, in low revenue customers, the cost of long lifetime customers is almost twice as that of short lifetime customers. Furthermore, a large number of transactions do not necessarily indicate a high lifetime value, and not all active customers contribute to large bank profits. The authors develop plausible explanations for the findings that go against available evidence in the literature, which can help managers focus their efforts on more profitable customers. The direction of future research may wish to consider a variety of retail banking business.

This research represents one of the few empirical inquiries into a phenomenon of great managerial and academic interest; however, several limitations are warranted to qualify our findings and encourage future research efforts.

First and foremost, additional research should extend the proposed empirical analysis to other product categories and industries. Although our data come from a large and established bank, further empirical analyses in other non-contractual contexts seem necessary. We provide a framework for analysis and application of this framework to other cohort databases should yield fruitful insights. The second issue that deserves attention is customer acquisition. The relationship of acquisition costs and lifetime profitability remains unexplored in this analysis because of unavailability of data. At this point, we do not know whether long- and short-life customers have differential acquisition costs or whether they differ in acquisition mode. Further research can address this issue with the availability of relevant data. Finally, the data used in this study spanned only two years. Although the two years yield multiple purchase opportunities, a longer duration of data may offer additional insights.

\section{ACKNOWLEDGEMENT}

This study supported by National Natural Science Foundation of China (70872087, 71002102, 71172133); "Shaanxi Universities Philosophy and Social Science Feature Academic Discipline Project" and "Xi' an Technological University Innovative Science and Research Team Project".

\section{REFERENCES}

Berger, Paul D., Nada I. Nasr. (1998). Customer Lifetime Value: Marking Models and Application. Journal of Interactive Marketing, 12(1), 17-30.

Blattberg, Robert C. and John Deighton. (1996). Manage Marketing by the Customer Equity Test. Harvard Business Review, 74(July-August), 136-144. 
Coffey, J. J. (2001). What is fund transfer pricing. ABA Bank Marketing, 33(9), 48-48. Colombo, Richard, \& Weina, J. (1999). A Stochastic RFM Model. Journal of Interactive Marketing, 13(3), 2-12.

Fader, Peter S., Bruce G. S. Hardie, and Ka Lok Lee. (2005). RFM and CLV: Using Iso-value Curves for Customer Base Analysis. Journal of Marketing Research, 42(4), 415-430.

Fader, Peter S., Bruce G. S. Hardie, and Ka Lok Lee. (2005). Counting Your Customers the Easy Way: An Alternative to the Pareto/NBD Model. Marketing Science, 24(2), 275-284.

Gupta, Sunil, Donald R., Lehmann, \& Jennifer, S. (2004). Valuing Customers. Journal of Marketing Research, 41(1), 7-18.

Jain, Dipak, Siddhartha S. Singh. (2002). Customer Lifetime Value Research in Marketing: A Review and Future Directions. Journal of Interactive Marketing, 16(Spring), 34-46.

Li, X. (2005). Design of Bank's Customer Profitability Accounting System Based on the Thought of Activity-Based Costing. Master's Degree Dissertation, Chongqing University, China.

Reinartz, Werner J. \& Kumar, V. (2000). On the Profitability of Long-Life Customers in a Non-contractual Setting: An Empirical Investigation and Implications for Marketing. Journal of Marketing, 64(October), 17-35.

Reinartz, Werner J. \& Kumar, V. (2003). The impact of customer relationship characteristics on profitable lifetime duration. Journal of Marketing, 67(January), 77-99.

Rust R. T., Katherine N. L., \& Valarie, A. Z. (2004). Return on Marketing: Using Customer Equity to Focus Marketing Strategy. Journal of Marketing, 68(January), 109-127.

Schmittlein, D. C., Donald G. M., \& Richard C. (1987). Counting Your Customers: Who They Are and What Will They Do Next? Management Science, 33(January), 1-24.

Schmittlein, D. C. \& Robert, A. P. (1994). Customer Base Analysis: An Industrial Purchase Process Application, Marketing Science, 13(Winter), 41-67.

Venkatesan, Rajkumar \& Kumar, V. (2004). A Customer Lifetime Value Framework for Customer Selection and Resource Allocation Strategy, Journal of Marketing, 68(October), $106-125$. 